\title{
DEVELOPMENT OF BEST PRACTICE TO MINIMISE OFF-TARGET DRIFT FROM HYDROGEN CYANAMIDE SPRAYS IN KIWIFRUIT ORCHARDS
}

\author{
R.E. GASKIN ${ }^{1}$, D.W. MANKTELOW ${ }^{2}$, B. MAY ${ }^{3}$ and S. MAX ${ }^{4}$ \\ ${ }^{I}$ Plant Protection Chemistry ${ }_{N Z}$, PO Box 6282, Rotorua, New Zealand \\ ${ }^{2}$ Applied Research and Technologies Ltd, PO Box 3415, Napier, New Zealand \\ ${ }^{3}$ Spray-Tec, PO Box 9227, Tauranga, New Zealand \\ ${ }^{4}$ ZESPRI Group Ltd, PO Box 4043, Mount Maunganui, New Zealand
}

Corresponding author: robyn.gaskin@ppcnz.co.nz.

\begin{abstract}
The use of air inclusion nozzles on airblast sprayers markedly reduced off-target spray drift in applications to dormant kiwifruit vines. The addition of a new drift-reducing adjuvant at rates of $\geq 50 \mathrm{ml} / 100$ litres maintained cane deposits at levels similar to those of conventional cone nozzle applications. The addition of the adjuvant at rates above $100 \mathrm{ml} / 100$ litres improved drift control in higher winds (ca $2 \mathrm{~m} / \mathrm{s}$ ). Prescriptions for AI nozzles and adjuvant use have been included in Best Practice Spraying Guidelines for New Zealand kiwifruit growers. Industry uptake was ca $40 \%$ by kiwifruit spraying contractors in the 2007 season and is expected to increase to $>80 \%$ by 2009 . Keywords: air inclusion nozzles, adjuvant, budbreak sprays, spray deposits.
\end{abstract}

\section{INTRODUCTION}

Hydrogen cyanamide is an essential tool that allows kiwifruit growers to achieve uniform and increased budbreak and flowering. However, it is a toxic chemical that presents a serious risk from off-target spray drift, which is an on-going concern for the industry. In 2005, the kiwifruit industry acknowledged that new technologies were required to reduce the likelihood of off-target spray drift and to improve the sustainability of hydrogen cyanamide use. An initial study identified that air inclusion (AI) nozzles, as opposed to standard cone nozzles, could decrease off-target drift by $>80 \%$ from sprays applied to bare canes (Gaskin et al. 2006). A series of studies since then has sought to develop the new nozzle technology and sound formulation prescriptions to recommend as 'Best Practice' for applying hydrogen cyanamide sprays to kiwifruit.

A field study in 2006/07 identified nozzle and adjuvant combinations that maximised hydrogen cyanamide spray deposits on target canes and minimised off-target drift (Gaskin et al. 2007). AI nozzles were confirmed to reduce downwind movement of spray up to $25 \mathrm{~m}$ from the sprayer by $>70 \%$, for sprays applied to dormant canes in the absence of a downwind shelter belt. However, the large droplet spray plume from AI nozzles gave reduced spray deposits on canes compared to standard cone nozzles, particularly as wind speed increased. The use of a novel sticker-spreader adjuvant with the AI nozzles was essential to increase cane deposits to equal those from standard cone nozzles, in wind speeds up to $5 \mathrm{~m} / \mathrm{sec}(18 \mathrm{~km} / \mathrm{h})$. The adjuvant was used at very low concentration $(\leq 0.05 \% \mathrm{v} / \mathrm{v})$ to reduce any risk of crop damage by budbreak sprays, and at this use rate the adjuvant had no effect on spray drift.

The combined nozzle and adjuvant technology has provided equivalent efficacy to conventional hydrogen cyanamide applications in 2 years of orchard trials (Gaskin et al. 2007; R.E. Gaskin, unpubl. data). The technology was cautiously recommended by 
Zespri as Best Practice for applying hydrogen cyanamide sprays in 2007 (Manktelow \& May 2007). The work reported here was undertaken to define the final nozzle, adjuvant and spray volume recommendations for Best Practice; in particular to determine the effects of increasing the adjuvant concentration on cane deposits and off-target drift. Additionally, spray applicators, mainly in the Bay of Plenty, were surveyed at the end of the 2007 season to determine the initial adoption level of the new technology and how they rated its performance.

\section{METHODS AND MATERIALS}

\section{Spraylab setup}

A single bay pergola structure $(5 \times 5 \mathrm{~m}$, by $2 \mathrm{~m}$ high $)$ was permanently constructed as a 'spraylab' in a large, open field near Rotorua. It was aligned at right angles to the prevailing SW wind. Wires were strung across the pergola canopy in both directions so that detached kiwifruit canes could be tied in at right angles to any direction of travel of the sprayer. Treatments were applied by spraying through the pergola and for at least $40 \mathrm{~m}$ before entering and after leaving it, with all nozzles operating. Upwind and downwind sides of the pergola were then individually sprayed, spraying in towards the pergola centre, with only that side of the sprayer operating.

\section{Treatments and sprayer setup}

Nine treatments were applied (Table 1) in December 2007. The study was conducted in light to moderate winds (mean of 1-2 m/s), but because wind speed cannot be controlled, a systematic study was not possible. Treatments 1 and 2 delivered the standard spray of 600 litres/ha, at a sprayer travel speed of $5.3 \mathrm{~km} / \mathrm{h}$, through industry standard cone nozzles. Treatment 3 delivered spray containing the sticker-spreader adjuvant through AI nozzles, at 600 litres/ha; this was the treatment cautiously recommended to industry in 2007. Treatments 4-9 used the same AI nozzles as treatment 3, but travel speed was reduced to $4.4 \mathrm{~km} / \mathrm{h}$ to deliver 700 litres $/ \mathrm{ha}$, and the adjuvant rate was varied.Application volumes in the latter treatments were increased because AI nozzles are seen to provide more patchy coverage on upper cane surfaces and have tended to give slightly lower net deposits than traditional fine droplet sprays. Nozzles for treatments 1 and 2 were Spraying Systems disks and cores (from the top: D2-45, D3-45, D3-33, D4-33, D3-35), operated at $2000 \mathrm{kPa}$. The AI setup used a combination of wide angle, hollow cone Albuz TVI ceramic AI nozzles (TVI-80-02, TVI-80-025 and TVI-80-03) in the top of the spray ring, and two narrow angle Agrotop AI flat fan nozzles in the lower two positions (TD-60-04, TD-40-04), operated at $1350 \mathrm{kPa}$. The sprayer was a 2007 model trailed Fantini airblast fitted with straightening vanes designed to deliver the least air from the top centre of the sprayer, with more and relatively even air output to each side. The sprayer fan was operated in the low gear option to deliver air velocities at the nozzles of ca $12-26 \mathrm{~m} / \mathrm{s}$ and an air output volume of ca $23,000 \mathrm{~m}^{3} / \mathrm{h}$.

Tartrazine food dye was included in all treatments $(5 \mathrm{~g} /$ litre $)$ as a tracer to quantify spray deposits. Hydrogen cyanamide was not included in any treatments as a strong correlation $\left(\mathrm{R}^{2}=0.79\right)$ between tartrazine dye and hydrogen cyanamide deposits has been determined previously (Gaskin et al. 2006). Two adjuvants were included in the studies. Latron ${ }^{\circledR}$ B-1956 (LB; Dow Agrosciences) is a resin-based surfactant regularly used by kiwifruit growers. Driftstop ${ }^{\mathrm{TM}}$ (DS; Nufarm Ltd) is a sticker-spreader that can increase spray deposits on dormant canes (Gaskin et al. 2006). Its use, at $50 \mathrm{ml} / 100$ litres $(0.05 \%)$, was endorsed by Zespri in 2007 as Best Practice for applying hydrogen cyanamide through AI nozzles to Hayward canes. In the current study, DS was used at rates of $300-1750 \mathrm{ml} / \mathrm{ha}$ (i.e. $50-250 \mathrm{ml} / 100$ litres).

\section{Cane deposit assessments}

One-year-old Hayward canes were used, which had been collected 5 months earlier and cool-stored until required. Twenty canes ( $>2 \mathrm{~m}$ length) were randomly selected and tied into the pergola (10 on each of upwind and downwind sides) immediately prior to each treatment application. After spray treatments had dried, each cane was sub-sampled by removing two $(20 \mathrm{~cm}$ long) sections located near the outside edge and in the centre 
of the bay. All cane samples were collected and processed as described in Gaskin et al. (2006). Briefly, they were measured to determine surface area and then washed to recover dye and quantify spray deposits. Deposits were calculated as dose $\left(\mu \mathrm{g} / \mathrm{cm}^{2}\right)$ normalised to $1 \mathrm{~kg}$ ai applied/ha. Results were analysed using ANOVA to determine the significance of the effects of treatment, cane replication and position in the pergola canopy on spray deposits.

\section{Drift deposit assessments}

Wind speed and direction were recorded throughout application of each treatment. Both mean and maximum wind speeds were determined (Table 1), using three wind speed meters $2 \mathrm{~m}$ above ground. One meter was positioned $15 \mathrm{~m}$ from the centre of the pergola plot, and the other two were stationed at $50 \mathrm{~m}$ up- and down-wind of the plot. Drift sampling was undertaken on the downwind side only of the sprayed plot because upwind drift deposits were $<1 \%$ of downwind deposits in previous studies (R.E. Gaskin, unpubl. data). Drift collection targets were vertical nylon trimmer lines ( $2 \mathrm{~mm}$ diameter; Sufix Trim'n Cut), held in place by metal clips on $5 \mathrm{~m}$ tall sample poles. Sampling was undertaken at three heights above ground; $0-2 \mathrm{~m}$ (up to the pergola canopy height), 2-3.5 $\mathrm{m}$ and $3.5-5 \mathrm{~m}$. Poles holding collectors were positioned at right angles to the spray line. Three replicates (approximately $2.5 \mathrm{~m}$ apart) were located at each of three positions on the downwind side of the pergola plot; $10 \mathrm{~m}, 15 \mathrm{~m}$ and $25 \mathrm{~m}$ from the centre of the sprayed plot, which equated to 5,10 and $20 \mathrm{~m}$ from the closest sprayer output. After spray applications had dried, the line collectors were immediately sectioned and sampled into separate zip-sealed plastic bags. They were washed in 25-100 ml distilled water and tartrazine dye deposits were quantified as for canes. Accurate line lengths were determined by weighing lines after wiping them dry. Deposits were calculated as dose $\left(\mu \mathrm{g} / \mathrm{cm}^{2}\right)$ normalised to $1 \mathrm{~kg}$ ai applied/ha. Results were statistically analysed using ANOVA to determine the significance of the effects of treatment, height above ground and distance from sprayer for off-target spray deposits (drift). A regression analysis of wind speed versus downwind drift resulting from sprays applied through both cone and AI nozzles was undertaken, using data from this study and a previous study conducted in winds up to $3.5 \mathrm{~m} / \mathrm{s}$ (Gaskin et al. 2007). All sprays through AI nozzles contained DS adjuvant, representing proposed Best Practice; all sprays through cone nozzles contained $\mathrm{LB}$, representing existing practice.

Spray applicator survey

A phone survey was conducted with 33 major kiwifruit spray contractors in Bay of Plenty, Northland, Auckland, Waikato and Nelson in November 2007. The questions asked included how many orchard clients they had, whether they used AI nozzles for applying budbreak sprays in 2007 , what percentage of sprayed area they sprayed with AI nozzles, whether they were satisfied with AI nozzle performance, if they used DS adjuvant in all AI sprays, what feedback they had received from their clients with respect to AI nozzle efficacy, whether they will spray/increase the area sprayed with AI nozzles in 2008 and if they would like more education on the new technology?

\section{Cane deposits}

\section{RESULTS AND DISCUSSION}

The effect of treatment on mean spray deposits on canes was highly significant $(\mathrm{P}<0.0001$; Table 1). The standard cone nozzle spray gave the highest deposit in low wind and, as expected, mean spray deposits were reduced as wind speed increased. Deposits on canes from the standard AI treatment (recommended as Best Practice in 2007) were lower than from the standard cone nozzle treatment in low wind, by about $30 \%$ (Table 1 ). When the spray volume was increased from 600 to 700 litres/ha under these conditions, the trend was for deposits to decrease further. The higher volume AI+DS50 treatments $(4 \& 5)$ were applied under conditions of the most fickle wind direction and with variable gusts, but increasing spray application volumes, from 600 to 700 litres/ha with the lowest rate of DS (50 ml/100 litres), did not benefit spray deposits under these conditions. 
At higher wind speeds $(\geq 1.7 \mathrm{~m} / \mathrm{s})$, AI treatments containing DS (100 and $250 \mathrm{ml} /$ 100 litres) provided similar mean deposits to the standard cone nozzle spray (Table 1). This was despite the AI treatments being subjected to more and higher maximum wind gusts than the standard spray. AI nozzles generally deposited sprays equally well on the up- and downwind sides, and on canes in centre and edge positions, of the pergola (data not presented).

TABLE 1: Deposits $\left(\mu \mathrm{g} / \mathrm{cm}^{2}\right.$, normalised to a $1 \mathrm{~kg} / \mathrm{ha}$ application of dye $)$ recovered from canes and downwind drift collection poles, from sprays applied through AI nozzles with varying rates of Driftstop adjuvant, compared to standard cone nozzles.

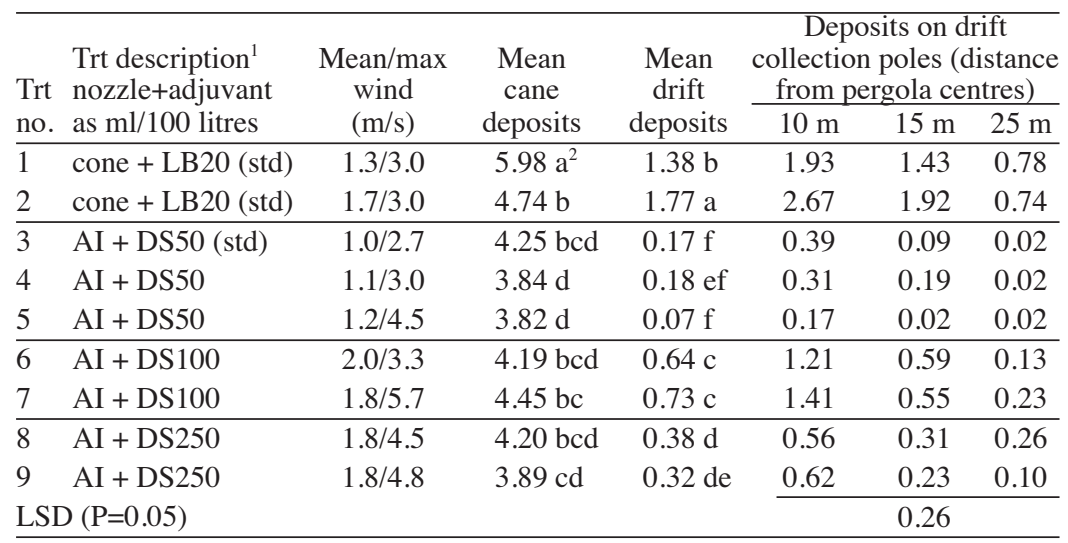

${ }^{1}$ (std) treatments applied in 600 litres/ha, all others in 700 litres/ha.

${ }^{2}$ Means within columns sharing common letters are not significantly different (LSD, $\mathrm{P}<0.05$ ).

\section{Drift deposits}

Treatment had a significant effect $(\mathrm{P}<0.0001)$ on drift (Table 1); on both horizontal distance from the sprayer $(\mathrm{P}<0.0001)$ and vertical height above the ground $(\mathrm{P}<0.002$, data not shown). At low wind speeds (1-1.3 m/s), AI+DS50 reduced mean drift (up to $5 \mathrm{~m}$ high and $25 \mathrm{~m}$ away from the pergola centre) by $>85 \%$, relative to the standard cone nozzle treatment (Table 1). At higher wind speeds (1.7-2 m/s), AI+DS100 and AI+DS250 reduced mean drift compared to the standard cones, by ca $60 \%$ and $80 \%$, respectively. This confirmed earlier studies (Gaskin et al. 2006), where DS at high concentration $(0.25 \%)$ significantly reduced drift (by $>80 \%$ ) from AI nozzles. Higher concentrations of DS reduced drift more in high winds.

Spray drift increased with wind speed (Table 1). Horizontal drift at $25 \mathrm{~m}$ distance was reduced by AI nozzles+DS by at least $97 \%$ in light winds $(1-1.3 \mathrm{~m} / \mathrm{s}$; treatments $3-5)$, and by $>65 \%$ in higher winds (1.8-2 m/s; treatments 6-9), relative to the standard sprays. Vertical drift above the pergola (i.e. $>2 \mathrm{~m}$ high) was $60-95 \%$ less with AI nozzles compared to cone nozzles (data not shown). Wind speed had the greatest effect on vertical drift, and in higher winds the highest rate of DS reduced vertical drift most. Increasing DS rate showed a definite trend of reducing drift. There was no obvious effect of spray volume (600 versus 700 litres/ha) on spray drift.

The comparison between AI and cone nozzles demonstrated that the general relationship between risk of spray drift with increasing wind speed was greater for cone nozzles (Fig. 1). Total drift movement with AI+DS increased less rapidly with increasing wind and was generally $<25 \%$ of that with cone nozzles, at wind speeds up to ca $3 \mathrm{~m} / \mathrm{s}$ $(11 \mathrm{~km} / \mathrm{h})$. These studies have resulted in the introduction of firm recommendations to kiwifruit growers in 2008 for the use of AI nozzles and Driftstop adjuvant to control hydrogen cyanamide drift (S. Max, Zespri, pers. comm.). 


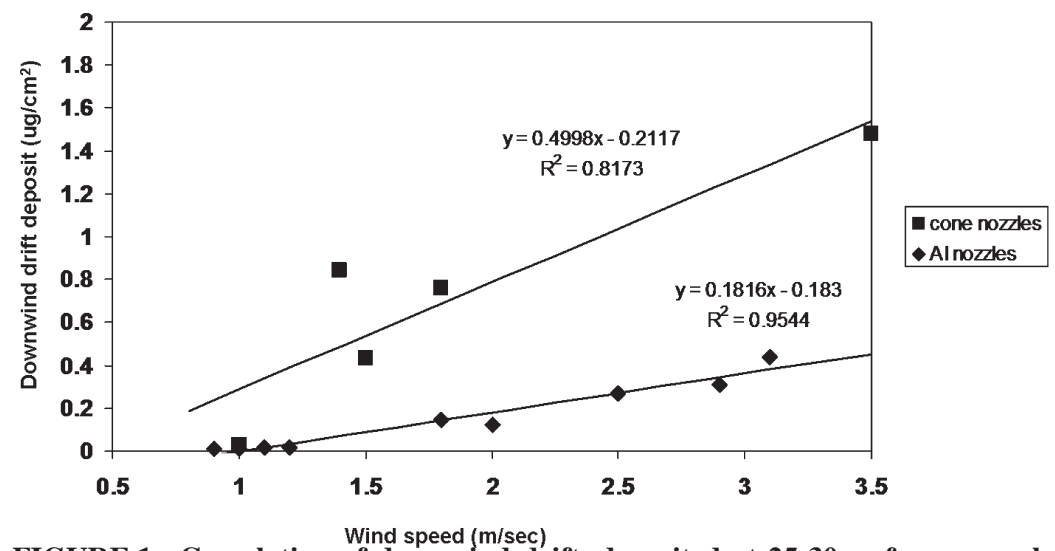

FIGURE 1: Correlation of downwind drift, deposited at $25-30 \mathrm{~m}$ from pergola centres, from cone nozzles+Latron B and AI nozzles+Driftstop with wind speed (data from all studies, including Gaskin et al. (2007)).

\section{Survey results}

Forty percent of the contractors surveyed had trialled AI nozzles in 2007. This level of uptake is considered high for a new technology, especially given there was an additional cost associated with its use (average $\$ 300$ to re-nozzle a sprayer plus $\$ 15 /$ ha for DS) and that it was not compliance driven. The thirteen contractors who used AI nozzles trialled them on an average of $47 \%$ of the area they sprayed, a total of $1362 \mathrm{ha}$. Use ranged from $95 \%$ down to $4 \%$ of the area sprayed. This indicated the range of comfort contractors had with the technology. It was notable that the highest user (\% of area sprayed) was involved in orchard trials of the technology in the previous season and the level of use likely reflects the confidence gained from being involved at an early stage.

Very positive feedback was received on how well the technology reduced spray drift and how visual the reduction was. The AI nozzles reduce drift through production of larger, more consistent sized droplets (Downer et al. 1995). In addition, these larger droplets reflect light less than small droplets, making any spray drift markedly less visible. Of the contractors who did not trial AI nozzles in 2007, nearly $40 \%$ said they would in 2008. A quarter said they would no longer be contracting. Of the remainder, one saw no need for the technology and all others were "possible" users. A common theme from the "possibles" was the need for more information and education on AI technology. With this provided, industry uptake is expected to increase to $>80 \%$ of kiwifruit spraying contractors by 2009.

\section{CONCLUSIONS}

The use of AI nozzles markedly reduced horizontal and vertical drift of airblast sprays relative to conventional cone nozzles. Prescriptions for AI nozzles, combined with a new drift-reducing, sticker-spreader adjuvant, to reduce off-target spray drift in applications to dormant kiwifruit canes have been developed. While spray deposits on dormant kiwifruit canes may be reduced by the use of the AI nozzles, the addition of DS adjuvant at rates of $\geq 50 \mathrm{ml} / 100$ litres can maintain cane deposits similar to those from conventional cone nozzle applications. The addition of the adjuvant at rates above $100 \mathrm{ml} / 100$ litres can be used to further improve drift control in higher winds or around sensitive areas. Prescriptions are now included in Best Practice Spraying Guidelines for New Zealand kiwifruit growers. Industry uptake was ca $40 \%$ by kiwifruit spraying contractors in the 2007 season and is estimated to be $>80 \%$ by 2009 . 


\section{ACKNOWLEDGEMENTS}

Thanks to R\&R Tractors, Te Puke, for delivery and use of the Fantini airblast sprayer and a tractor; Stefan Gous for use of the trial site. Technical assistance was provided by Kevin Steele, Rebecca van Leeuwen, Alison Forster, Amin Pathan, Mark Geddes, David Horgan and Guy Arnold. Juanita Dunn of HortResearch conducted the phone survey of contractors. Funding was provided by New Zealand Kiwifruit Growers Inc. and the MAF Sustainable Farming Fund.

\section{REFERENCES}

Downer RA, Wolf TM, Chapple AC, Hall FR, Hazen JL 1995. Characterising the impact of drift management adjuvants on the dose transfer process. In: Proceedings of the $4^{\text {th }}$ International Symposium on Adjuvants for Agrochemicals. Gaskin RE ed. FRI Bulletin No. 193. Pp. 138-143.

Gaskin RE, Manktelow DW, Steele KD 2006. Adjuvant and application technologies to minimise off-target drift from kiwifruit sprays. New Zealand Plant Protection 59: 217-222.

Gaskin RE, Manktelow DWL, May W 2007. Adjuvant and air inclusion nozzles reduce hydrogen cyanamide spray drift in kiwifruit orchards. Proceedings of the $8^{\text {th }}$ International Symposium on Adjuvants for Agrochemicals, Columbus, Ohio, USA, 6-9 August 2007. Poster abstract 07. ISBN 978-0-473-12388-8.

Manktelow DWL, May W 2007. Kiwifruit Spraying: Application of Bud Breaking Sprays. Notes from the Zespri/KGI/SFF 2007 Workshops to present Best Practice Guidelines for minimising potential off-target impacts of bud break sprays. Zespri Grower internet publication, 11 pp. www.zespricanopy.com (accessed 20 May 2008). 